\title{
Organization of Monitoring of the Forest Environment in the Sanitary Area Refinery
}

\author{
V. A. Zakamskii
}

\begin{abstract}
This paper aims to show how to organize the monitoring of the evaluation of the impact on the forest environment in the sanitary area of the refinery. It is proposed to use the methodology of biological networks, which includes problem solving for the assessment of anthropogenic impact of industrial enterprises in forest areas and analysis of state data growing vegetation. The obtained results can be used in the control and inventory of anthropogenic forests near chemical plants, recreational and other degradiruem objects.
\end{abstract}

Index Terms-Anthropogenic impact on the environment, forest plantations, monitor, refinery.

\section{INTRODUCTION}

Protection of nature and the environment associated with the rational use of natural resources. In industry, you must know that you can change and what you cannot do. To what extent may affect the land, water resources, flora and fauna, for the preservation of the human environment. Therefore, the researchers are important tasks to minimize the negative impact on nature through the development of monitoring technologies in particular for the most important industries, especially chemical events.

The branch of science in the field of monitoring and control of forest objects of human nature gained a lot of experience. A variety of methods and ways to assess the increasing impact of various factors, primarily anthropogenic, on forest ecosystems necessitates to use a systematic approach to the study of problems in the functioning of forest ecosystems, based on the principles of stabilization and ways to increase [1].

\section{RESULTS AND DISCUSSION}

The analysis of the literature, research of the past years, the stock material held on the first phase of work, revealed that the main factors of possible deterioration of the ecological status of forest vegetation and its sustainability for the territory of the refinery following:

Natural factors (abnormal weather phenomena), including:

1) Storms, hurricanes, causing windthrow and windbreak

2) Drought, causing the deaths of mainly spruce and fir

3) Abnormal frosts, causing damage to oak, maple, etc. as well as for example, deciduous species (Birch)

Manuscript received September 1, 2014; revised December 16, 2014

V. A. Zakamskii is with the Volga state University of Technology, Yoshkar-Ola, Russia (e-mail: ZakamskijVA@volgatech.net).
4) Flash numbers of ungulates

5) Invasion of insect pests

6) The spread of fungal diseases

Anthropogenic factors:

1) Atmospheric industrial pollution;

2) Soil pollution with oil products in the production and transportation of oil;

3) Waterlogging in places gaskets linear engineering

4) structures (roads, pipelines)

5) Forest fires

6) Recreational digression

Abnormal weather phenomena can be viewed as insurmountable factors for organized monitoring of forest ecosystems. Note, however, that can line up a certain ecological chain of consequences, for example: extreme cold and prolonged drought causes weakening and mortality of individual trees. Distracted plantations is an intense multiplication of pests and diseases, further added to the effects of acid rain. As a result of unregulated recreation treads and compacted soil, as a consequence damaged active part of the root system. Overeat shoots overly bred wild ungulates animals. Based on all the above, the process of forest destruction starts to perform its negative role.

Thus, the task of monitoring of forest ecosystems must take into account the effects of the climatic anomalies and navigate to minimize damage to other factors, the effect of which is amplified by the weak state of the vegetation and disturbance of forest ecosystems by natural factors.

Atmospheric industrial pollution. First, for the diagnosis of air pollution, you can use the values projective cover and composition of lichens and mosses on the trunks of trees. Lichens and forest mosses are one of the most vulnerable components of the ecosystem, influenced by atmospheric pollution. Secondly, industrial pollution appears on the leaf apparatus. It is recommended to use surveillance conifers (particularly spruce, fir and other) due to the reduction of the age of their needles, the decrease in the degree of koennte.

Growns of trees, the appearance of the leaf apparatus of chlorosis (dyeing in different colors damaged parts of pine needles and leaves) and necrosis (death of tissue sheet and discoloration).Note, however, that the chlorosis and necrosis can occur as a result of pollutants, but also for other reasons: because of the high and low temperatures, drought, lack or excess of nutrients in the soil, waterlogging of the root systems, the activity of insect pests and various pathogens.

\section{A. Recreational Use}

One of the factors having a negative impact on the forest ecosystems of the territory near the refinery is and recreational use of forests. When visiting forests largely associated with the gathering of forest products is a complex effect on all components of the ecosystem. The main impact 
associated with trampling and mechanical damage all components of the plant. Trampling of the living ground cover, seeding, undergrowth undergrowth in the lower tier of the stands leads to mechanical damage to the least resistant plants, which primarily include the forest mosses, shrubs, forest herbaceous species. Trampling also leads to compaction litter and upper soil horizons of the soil, changing their water-air properties, which in turn affects the conditions of functioning of root systems of plants, living ground cover and stand Intensive trampling over time leads to destruction, erosion of top soil layers, where in the forest phytocenoses concentrated the bulk of nutrients.

In the study area plots, special attention should be given to the availability of Parking and square path network, damage to trees, saplings and undergrowth. Researchers there are five stages recreation. Well diagnosed can be considered as three main stages we can agree with that and use friderici monitoring tests.

Stage I is characterized almost undisturbed plant communities similar to natural forests. At stage III, the land of the living ground cover significantly different, its density is close to 1 stage, the ecosystem viable, typically the herb layer consists of grains and grasses that are resistant to trampling. . Stage V stage is characterized by severe degradation of soils and vegetation, forest litter and humus destroyed. On the territory of the observed erosion and deflation of soils, trees begin to die, one of the reasons is damaging their root systems. It is established that when the embossed surface to the mineral horizon exceeds $30-40 \%$ plots the death of more than $50-60 \%$ of the trees are inevitable.

In almost all cases it should be borne in mind that when recreation use and not disturbed the entire area of the forest. As most of the rest moves on the part of the territory.Therefore, usually forest ecosystems in the places visited by tourists represent a mosaic of different stages of recreational digression.

\section{B. Soil Erosion}

Erosion in forest areas is associated firstly with crown densities isagoge ground cover and change it on the weedruderal; and secondly with water flushing, forest litter and humus horizon; and third in the exposure of the roots of woody plants.

\section{Waterlogging}

Waterlogging can be a response to planning or other engineering measures, such as those associated with construction of linear structures (roads, pipelines, industrial buildings) are found in appearance as part of the living ground cover species-hygrophytes, ncreased moisture to the root zone of the soil and as a consequence decreased viability of some species of woody plants and even their death.

For the identified factors monitoring of forest ecosystems to assess the status of forest vegetation it is advisable to do using the metrics of different origin damages on the same plots and routes. It is important to follow the principle of complex organizations.

The work involves the systematization of knowledge on environmental monitoring (monitoring of forests) from the point of view of understanding of the forest ecosystem as a functional whole, arising on the basis of interdependence and causal relationships that exist between the individual components of natural complexes. In this direction the forest Fund of Russia (and in many countries of the world) opens prospects for monitoring of forest lands on a geographical basis. However, various aspects of forest land use, in particular for oil refinery complexes, require different assessment criteria. In this case, the area adjacent to the refinery (refinery) acceptable biological monitoring, i.e. the status of the biota, and its response to anthropogenic forcing, functions, status and deviations this function from the normal natural state at the population level forest communities [2].

Proceeding from the above, the main tasks of ecologists refinery should be aimed at preserving and restoring natural forest complexes and characteristic vegetation. Adverse should be considered anthropogenic and zoogenic, vicepresidencia, digression-demutation fluctuations associated with the death of major components in plant communities, the loss of the living ground cover aesthetic appeal and soil functions. And in the immediate area of the junction of the natural landscapes of the territory of the refinery should not be irreversible change, disrupting the structure and composition of typical indigenous forests. Therefore, the aim of monitoring of forest ecosystems buffer zone refinery can be formulated in the following way - it control over the condition of the vegetation and soil cover, for the timely detection and prevention of adverse changes on the object of observation [3].

Thus, the theoretical rationale for the development of a system of indicators for monitoring forest ecosystems are the basic doctrines of the dynamics of the components in the plant communities and lesovodstvennye environmental control in the organization of monitoring.

To solve the tasks we have successfully applied the international project on forest monitoring called the international cooperative programme on assessment and monitoring effects of air pollution on forests (ICP-Forest) under the Convention on the transboundary transfer under the auspices of the economic Commission for Europe United Nations. In the Russian Federation forest monitoring began with the 1995 Federal forestry service. Get information must ensure representativeness, validity and comparability of research results, on the basis of the principle methods of observations, estimates and projections and maximize the average detection probability of damage for a given level of total expenditure. Based on the above solution was selected on the application of the method of biological networks and route reconnaissance survey of forests in the buffer zone refinery [4].

According to the research results generated by the local system of monitoring of forest ecosystems can be built systematically and organizationally in a single European system of regional monitoring of forest condition using biological network in the framework of the International cooperative programme on assessment and monitoring effects of air pollution on forests (ICP-Forest) [5].

Studies were conducted on the items of permanent records, located in the units of blocks forestry and sanitary area refineries. The centers of point was chosen not closer than $40-50 \mathrm{~m}$ from the edge of the forest, roads, power lines, 
fence. The layout of item constant consideration is given on the schematic map.

Item a was noted using a GPS satellite navigation system. In the center point of the permanent accounting column with the appropriate numbering or out of the tree on which the paint was applied around the circumference of the band and was assigned an item number permanent account. On each item of the permanent account laid 4 accounting points in the directions along the sides of the light at a distance of 25 $\mathrm{m}$ from the centre. In the center registration point was set column (0.5-0.7 m). From THE center of each was measured the exact distance to the next six best-coniferous (hardwood) trees. The distance was measured with a precision of $10 \mathrm{~cm}$ to the center of the trunk. On account of the trees paint was applied to their room and the band at the height of $1.3 \mathrm{~m}$. For each item of the permanent records in a special account forms are entered parameters. On the first form did the sketch plan for the location of point a, the four registration points, the center point of the permanent accounting and account trees. Noted the existence of damage and their representation in points (1. no damage 2. weak damage - less than 25\%, 3. medium - 25-50\%, 4. strong-50-75\%, 5. full-bolee $\%$ ). Then performed a full very rare all trees I. 2 tiers on the status categories and elements of the forest. Data are very rare, placed on a special account forms. Indicate the nature of the damage to the trees, their extent and the reasons that caused them. In the very rare necessarily indicate the population of trees of different categories stem the incidence of pests and diseases. Windfall, snow breaks considered separately indicating the time of their formation.

The number of seedlings by species, age, height, and condition were assessed on account of band width of $2 \mathrm{~m}$ and a length of $50 \mathrm{~m}$ on the line connecting the North and South points of consideration. On the same lane was determined by the density, height, and condition of the forest floor. The data entered in the user form.

On account of the band-provedenii linear valuation of the surface condition of the soil and the condition of the living ground cover with the aim of determining the stage of degradation, soil erosion, disturbance of forest communities of wild and domestic animals. Has identified the following main categories of soil:

1) Normal for the type of forest living ground cover

2) Rogoway living ground cover

3) Weed live groundcover

4) Dead cover with litter

5) Same with compacted bedding

6) The same to the humus horizon

7) The same to the illuvial horizon

8) Pitted

9) Path

10) Fires

11) And other

For the categories of surface soil indicated the main reasons for the differences from the natural state (transformation):

1) Continue to use

2) Recreation

3) Lighting

4) Thickening-shading

\section{5) Erosion}

6) Fires

7) Activities of animals

\section{8) And other}

Data entered into the form.

For live ground cover was determined (eye) the projective cover types and tiers for the entire trial area bounded by the points of measurement. Data entered into the form, with the description of plant communities celebrated the full floristic composition of the plant community and defined in detail the projective cover of each tier and each species.

Route studies conducted on the lines connecting the PPU. Their main task is to identify forest areas that are subject to strong digression was found, erosion, and also to quickly identify the threatened damage, injury or dying forests, to assess the sanitary condition of the plants with broken and lost stability and examination of pests and forest diseases. On the routes defined in the band observation stage digression was found, revealed forests damaged by diseases and vreditelyami routes also determined the localization of plant species requiring special protection (Red book).

Data are entered in a special journal with the application copies of the afforestation plan showing the route. To anchor points on the route studies to a geographic coordinate grid, as well as to determine the absolute elevation used electronic radio navigation GPS device. Fixed waypoints recorded in the memory device and used for laying a course on the map, put in a storage device the GPS receiver.

Detection of areas with reduced viability of plantations neobaroque and additional plots were not laid.

For the indicated direction of the organization and monitoring of forest communities, it would be advisable to combine research specialists in the field of farming, the anthropogenic forests refineries creating a single international project.

The ultimate goal of this work is the representation of the management and Supervisory bodies of monitoring technologies for predicting the state of the environment and lesovodstvennye environmental monitoring sustainability of forest communities in the sanitary area of the refinery other enterprises of the chemical industry to prevent and eliminate pollution.

This will be solved the following tasks:

1) Identification of adverse impacts on natural systems and the organization of the monitoring components (environment, forest ecosystems, soil);

2) The establishment of necessary and sufficient characteristics of natural objects, vegetation and soil to control their condition;

3) Development and substantiation of optimal methods of accounting, analysis, forecast for the periodicity and frequency of monitoring;

4) The development of methods and ways of modeling the collected information to effectively detect changes in the environment, vegetation and soil cover;

5) Design measures to prevent adverse effects on the environment, vegetation and soil and eliminate pollution.

6) Determining the relation of the organizers of the monitoring and administrative bodies to prevent adverse changes to the environment, vegetation and soil cover. 
The main expected results will include:

1) Technologies and methods of organization of continuous observations, with preliminary assessment of the ecological status of forest vegetation in close proximity to the refinery;

2) View and approbation create regular biological network data collection and convenient forms of fixing the results of evaluation and monitoring sustainability of natural systems;

3) Identification of key parameters for consideration of quantitative and qualitative characteristics of forest vegetation from natural and anthropogenic factors; Is The determination whether the combination of the method of biological networks and selective transact now survey of forest in the sanitary area refineries.

\section{CONCLUSION}

Thedevelopedmonitoring system, the method of assessment of contaminated areas and data status of forest vegetation is recommended for the control and inventory of anthropogenic forests near oil refineries and other degradiruem territories.

What possible consumers expected results should be considered:

1) Venture refining industry other chemical production, altering the environment;

2) Ministries and departments, supervising the management of natural resources, ecology, land use, forestry.
The work was done in collaboration with ecologists and administration of Mari El refinery on the topic "Project monitoring of forest ecosystems and soil Mariisky NPZ" research Report/Marstu: No. 06.220/06. Yoshkar-Ola, 2008 -10 .

\section{REFERENCES}

[1] V. A. Zakamskii, Monitoring Deciduous Plant Communities Refinery, Saarbrücken, pp. 10-12, 2013.

[2] V. A. Zakamskii, Evaluation Results Naturally Emerging Vegetation in the Sanitary Area of the Refinery, Przemys, vol. 28, pp. 16-18, 2013.

[3] V. A. Zakamskii, "Organization of monitoring of forest phytocenoses in the sanitary area of the refinery," in Proc. LXXVIII International Research and Practice Conference, London, March 21-March 26, 2014, pp. 62-63.

[4] V. A. Zakamskii, "Monitoring and silvicultural and ecological control of forest communities in the sanitary protection zone of the oil refinery," in Proc. Materialy Euro Eco International Symposium, Hannover, November 28-29, 2013, pp. 151-152.

[5] Y. G. Fry and V. A. Zakamskii, Monitoring of Forest Ecosystems: The Manual, Yoshkar-Ola, 2006, pp. 61-66.

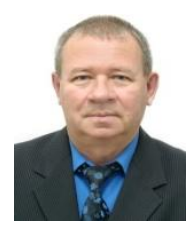

V. A. Zakamskaii defended his Ph.D. thesis in the field of forest crops, plant breeding, seed and urban greening. $\mathrm{He}$ is an associate professor of Forestry Volga State University of Technology, Yoshkar-Ola, Russia. His research interests include issues related to the organization of monitoring of places of impact on the forest environment of industrial enterprises and recreation. $\mathrm{He}$ is the author of Bolu 150 publications in national and international publications. In 2013 he was awarded the title "Honored scientist of Europe".424000, Mari El, PE-Ola,Lenina, House 3. 